Anuário do Instituto de Geociências - UFRJ
ISSN 0101-9759

FORAMS 2006

\title{
Taphonomy of benthic foraminiferal tests from the Jurujuba Sound, Guanabara Bay, Rio de Janeiro, Brazil
}

\author{
Patricia B. P. Kfouri-Cardoso ${ }^{1}$; Marcello Guimarães Simões²; Sabrina Coelho \\ Rodrigues $^{3}$; Beatriz Beck Eichlerr ${ }^{1}$; Silvia Helena de Mello e Sousa ${ }^{1}$; \\ Patrícia Beck Eichler ${ }^{4} \&$ Rubens César Lopes Figueira ${ }^{5}$ \\ ${ }^{1}$ Instituto Oceanográfico da Universidade de São Paulo/USP, São Paulo, SP, Brazil \\ pkfouri@io.usp.br \\ ${ }^{2}$ Instituto de Biociências, Universidade Estadual Paulista Júlio de Mesquita Filho/UNESP, \\ Botucatu, SP, Brazil \\ ${ }^{3}$ Instituto de Geociências, Programa de Pós-graduação, GSA, IGc/USP, \\ Universidade de São Paulo/USP, SP, Brazil \\ ${ }^{4}$ Delaware Geological Survey, University of Delaware, Newark, DE, U.S.A. \\ ${ }^{5}$ Universidade Cruzeiro do Sul/UNICSUL, São Paulo, SP, Brazil
}

Besides the potential for post-mortem transport, foraminiferal tests deposited in shallow water conditions are also potentially subject to abrasion, fragmentation, bioerosion and dissolution/corrosion. The extent in which these processes act on the foraminiferal tests will depend on some intrinsical factors, such as, composition, microstructure, architectures, ornamentation, shell thickness, and test porosity. Microhabitat, substrate and water biogeochemical conditions, and exposure time to the taphonomic processes mentioned above play a role in the preservation of foraminiferal tests. In other words, the destruction of foraminiferal tests depends on the interplay of extrinsical and intrinsical factors. The resulting taphocoenoses may be a modified and biased portrait of a given living assemblage in terms of taxonomical and ecological composition. In the tropical shallow water, marine environments dissolution/ corrosion of the calcareous tests is one of the main processes acting in the destruction of benthic foraminiferal tests. In this study, we present a taphonomic analysis of benthic foraminiferal tests found in one $1.88 \mathrm{~m}$-thick, sandy core of

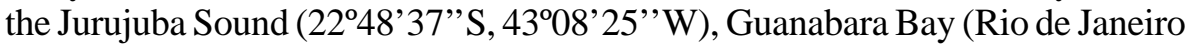
State). This area was chosen taking into account the impact by urban sewage discharges. Foraminiferal faunas, their taphonomy and associated geochemical analysis may all be combined to reveal the extent of these anthropogenic impacts on the study area. Analyses include sediment grain size, heavy metals, taxonomic composition and the study of the taphonomic signatures (e.g., abrasion, fragmentation, dissolution/corrosion) of individual foraminiferal tests. Special attention was given to the tests found in the upper $50 \mathrm{~cm}$ of the sediment core, 
which correspond to the taphonomically active zone (TAZ). The foraminiferal fauna is dominated by calcareous species (Ammonia tepida, Elphidium spp. Quinqueloculina seminulum). Results suggest that the microfaunal composition, abundance and density in the studied superficial sediment layers is related to acid $(\mathrm{pH}<7)$ pore water conditions, with associated high concentrations of Zn. Not surprisingly the foraminiferal tests are typically corroded or broken. Consequently, the preserved microfaunas in the analyzed core are biased in relation to the original living benthic assemblage. Finally, the composition and density of the foraminiferal tests will not necessarily mirror the natural conditions of a given area, but rather may be influenced by the sediment geochemistry and the taphonomic processes operating in the study area. These observations have obvious implications for the paleoecologic analysis. 